\title{
Forecasting the demand for electric vehicles: accounting for attitudes and perceptions
}

\author{
Aurélie Glerum * \\ Lidija Stankovikj * \\ Michel Bierlaire * \\ 23rd March 2013 \\ Report TRANSP-OR 120217 \\ Transport and Mobility Laboratory \\ Ecole Polytechnique Fédérale de Lausanne \\ transp-or.epfl.ch
}

Michaël Thémans ${ }^{\dagger}$

\begin{abstract}
In the context of the arrival of electric vehicles on the car market, new mathematical models are needed to understand and predict the impact on the market shares. This research provides a comprehensive methodology to forecast the demand of a technology which is not widespread yet, such as electric cars. It aims at providing contributions regarding three issues related to the prediction of the demand for electric vehicles: survey design, model estimation and forecasting. We develop a stated preferences (SP) survey with personalized choice situations involving standard gasoline/diesel cars and electric cars. We specify a hybrid choice model accounting for attitudes towards leasing contracts or practical aspects of a car in the decision-making process. A forecasting analysis based on the collected SP data and market data is performed to evaluate the future demand for electric cars.
\end{abstract}

\section{Key words}

Electric vehicles, discrete choice modeling, demand prediction, transportation, attitudes and perceptions, hybrid choice models, fractional factorial design.

*ÉCOLE POLYTECHNIQUE FÉDÉRALE DE LAUSANNE (EPFL), School of Architecture, Civil and Environmental Engineering (ENAC), Transport and Mobility Laboratory (TRANSP-OR), aurelie.glerum@epfl.ch, lidija11@gmail.com, michel.bierlaire@epfl.ch

${ }^{\dagger}$ ÉCOLE POLYTECHNIQUE FÉDÉRALE DE LAUSANNE (EPFL), Vice-Presidency for Technology Transfer (VPIV), Transportation Center (TRACE), michael.themans@epfl.ch 


\section{Introduction}

Electric vehicles have been proposed on the car market for many years, but in a rather marginalized way. Recently, governments and public authorities have set strategic goals in terms of energy efficiency and amount of allowed $\mathrm{CO}_{2}$ emissions. As a consequence, many car manufacturers are launching electric vehicles on the market on a large scale. As a response to these changes in the market, the demand for electric vehicles is likely to increase and the market shares of the different fuel technologies might be affected in a significant way.

Electricity has major advantages compared to gasoline or diesel: the vehicles do not emit carbon dioxide and greenhouse gases. Nevertheless they also have drawbacks: their range is limited, a full charge of the battery requires up to 8 hours (before fast charges are available) and currently, few charging stations are available. It is therefore critical for car manufacturers to define the right pricing strategies and to understand their impact on individuals' vehicle choices.

The objective of this paper is to present an integrated methodology to forecast the demand for electric vehicles, from data collection to prediction. As noted by Daly and Rohr (1998), the literature is scarce in methods dealing with issues related to the application of models designed to forecast demand for new alternatives, most of the attention being given to the model estimation only. Moreover there are few rigorous publications that integrate several methodologies to develop a model that can be applied for forecasting.

Although the general framework of the model we developed is relatively standard, we address in the paper several methodological issues which are critical to obtain an operational model. In particular, the integrated methodology involves the following features:

1. A customized choice situation design using the iterative proportional fitting (IPF) technique;

2. The specification of a model for the whole market, derived from a stated preferences (SP) model;

3. The inclusion of an attitudinal dimension in the choice model;

4. The derivation of the key indicators for forecasting, that is, market shares, elasticities and willingness to pay.

Moreover the model is validated and applied for a real case, where the purpose is to evaluate the demand for electric vehicles on the Swiss market. 
The case study is based on the result of a collaborative project between Renault Suisse S.A. and EPFL's Transportation Center (TraCe). The aim of this joint research was to develop an appropriate pricing scheme for the electric car models that Renault was about to launch, i.e. the compact car Fluence and the sub-compact car Zoé, and to identify their potential customers. For that purpose, we collected SP data on individuals' preferences among three vehicle types: their own vehicle, an analogous gasoline or diesel Renault and a similar electric Renault.

This research builds upon the findings presented in Glerum et al. (2011).

The document is constructed as follows. Section 2 presents a literature review. Section 3 describes the data collection, including a description of the survey, the sampling protocol and the experimental design. Section 4 presents the specification, estimation and validation of the SP model. Section 5 describes the transformations applied to the SP model such that it can be used in an operational way. Section 6 presents market forecasts under different price scenarios and an analysis of demand indicators. Section 7 discusses concrete learnings drawn from the application of the model for the industrial partner. Section 8 concludes on the main outcomes of the research and outlines the future steps.

\section{Literature review}

As introduced in Section 1, this paper aims at presenting an integrated methodology to predict the demand for electric vehicles. In particular, this methodology focuses on three important aspects of demand forecasting:

- Survey design

- Model specification and estimation

- Model application

In this section, we review how each of these steps are separately addressed in the literature on car demand modeling.

Several SP surveys have been conducted to collect data on vehicle choice. Mannering and Train (1985) mention the fact that individuals may respond differently to hypothetical choice situations than to real-world contexts but they highlight the importance of SP surveys to investigate the impact of car characteristics which are absent from the market on the purchase choice. SP surveys are thus broadly used to model vehicle demand when new technologies are introduced. Beggs et al. (1981) present choice situations involving both 
gasoline and electric vehicles. Train (1980), Brownstone et al. (1996), Dagsvik et al. (2002), Alvarez-Daziano and Bolduc (2009) and others additionally introduce other alternativefuel vehicles in the choice contexts. The presentation of customized choice situations has been explored by several researchers. Bunch et al. (1993) first collect data on the category of vehicle that the respondent would buy for his next purchase and then design choice situations based on reported information. Achtnicht et al. (2008) include price characteristics of the future vehicle itself. Ewing and Sarigöllü (2000) and Horne et al. (2005) introduce a vehicle closely matching the respondent's own vehicle. We also propose customized choice situations in our SP survey, emphasizing more on brand and model information. SP surveys require the development of experimental designs. Most of the experimental designs considered in the literature on SP surveys for automobile demand are fractional factorial designs (Bunch et al., 1993, Brownstone et al., 1996, Ewing and Sarigöllü, 2000, Horne et al., 2005). We propose in this paper a post-processing of such a design that provides a more balanced experiment.

Discrete choice methodology has been widely applied to analyze the demand for alternativefuel or electric vehicles. Brownstone and Train (1999) present a mixed logit model with random coefficients relative to the fuel type. Dagsvik et al. (2002) also allow the coefficients assessing the effect of the fuel type on the choice to be random, but in addition, they take into account the correlation between two successive choice situations which depend on each other. Brownstone et al. (1996) involve vehicle transaction decisions, that is, adding a vehicle into the respondent's household, replacing or disposing of an existing vehicle. Schiraldi (2011) also proposes a model of vehicle transaction, which involves a temporal dimension and includes both new and used car markets. Mueller and de Haan (2009) investigate the impact of incentives on car purchase. The recent interest in the inclusion of attitudinal factors into discrete choice models (DCM) (McFadden, 1986) has impacted on the car demand literature. Ewing and Sarigöllü (2000) cluster individuals according to their attitudes towards the environment and the technology and assess the effect of this segmentation on the choice. Achtnicht et al. (2008) define an indicator of 'eco-orientation' and analyze its impact on the choice. The development of hybrid choice models (HCM) (Walker, 2001; Walker and Ben-Akiva, 2002; Ben-Akiva et al., 2002) has led to an integrated approach to evaluate the impact of attitudes on choice, by combining structural equation models (SEM) and DCMs. Alvarez-Daziano and Bolduc (2009) apply an HCM to analyze the demand for electric vehicles. In particular, they assess the effect of individuals' environmental concern on vehicle preferences. In this paper, we propose an 
HCM accounting for attitudes towards leasing and convenience of the car.

Since SP data does not perfectly reflect real-life situations, models estimated on such data must be adjusted before they can be used for forecasting. This issue has been addressed by Brownstone et al. (1996) among others in the case of demand for electric vehicles and other alternative-fuel vehicles. Brownstone et al. (2000) apply a model jointly estimated on both revealed preferences (RP) and SP data to obtain more realistic market shares for alternative-fuel vehicles. As raised by Bunch et al. (1993), the corrected model can be applied to simulate policy scenarios related to the introduction of a new vehicle type. Beforehand, a 'base case' scenario must be defined, in order to represent the potential market situation when all infrastructures for the new vehicles are available (Train, 1986). Scenarios simulating the demand for alternative-fuels have been investigated by Ewing and Sarigöllü (2000) and Daziano and Bolduc (2013) among others. In the literature, forecasting analyses include the derivation of elasticities (Dagsvik et al., 2002) or willingness to pay (WTP) indicators (Daziano and Bolduc, 2013). In a different domain of application, Abou-Zeid et al. (2010) investigates the effect of interacting a latent variable with a cost variable on an indicator of WTP, leading to a more complete understanding of the population heterogeneity in terms of cost perception. We include in our analysis these aspects despite the high complexity of our mathematical model.

This research builds on the literature by proposing a complete methodology to forecast the market share of a non-existing technology, accounting for individuals' attitudes.

\section{Data collection}

The methodology presented in this paper is applied on a case study, where we evaluate the demand for Renault electric cars on the Swiss market. We conducted a survey at the beginning of 2011 in order to collect data on individuals' preferences in terms of vehicles. The survey was designed in two phases: the first phase (phase I) gathered information about the cars in the respondents' households and the second phase (phase II) was an SP survey with hypothetical choice situations. The online questionnaires were managed with the help of the market research institute GfK Switzerland.

\subsection{Stated preferences (SP) survey}

The two-phase survey was structured as follows.

Phase I was mainly designed to collect information about the characteristics of the cars within the respondents' households, that is their makes, models, fuel types, engine dis- 
placement and versions. This information was used to create personalized choice situations for phase II. In addition, data about the respondents' mobility habits and socio-economic information were collected.

Phase II was launched two weeks after phase I and consisted of two important parts: choice situations and opinion statements.

Five choice situations were shown to each respondent. In each of them three different cars were proposed: a car similar to his own vehicle, the analogous model from the Renault brand (also with a combustion engine) and a similar model in the Renault product line of electric cars. In the case where the respondent owned a Renault car, only the last two options were presented. In each choice situation, the respondent was asked to indicate the car he would choose, if he had to change his car at present.

By presenting a car which is similar to the respondent's own vehicle, we aim at providing a realistic choice set. In the research based on SP experiments, it is common practice to use an existing alternative to construct a hypothetical one (see e.g. Train and Wilson, 2008).

An example of a choice situation for a respondent with a non-Renault car is shown in Table 1. Each vehicle is characterized by a list of attributes defined in collaboration with Renault. These attributes include make, model, fuel type, possible governmental incentive, maintenance costs, fuel/electricity costs and battery lease. Given that car drivers may decide to either purchase or lease a car, we additionally display both purchase price and monthly leasing price of each car. Regarding the electric vehicles, two models can be proposed to a respondent: (i) the compact car Fluence Z.E. if he owns a rather large car or (ii) the sub-compact car Zoé if he owns a smaller car. Leasing the battery of electric vehicles is a specificity of Renault's business strategy. It is applied in Switzerland, but also in other countries such as France and Germany.

The definitions of the analogous gasoline/diesel and electric vehicles from the Renault brand are determined from the information on the respondent's car given in phase I, such that the segments of the respondent's car, the analogous Renault model with a combustion engine and the electric vehicle match at best.

In Table 1, the entries in normal font represent data directly reported by the respondent during phase I or inferred from a database containing characteristics of the cars currently on the Swiss market (based on the respondent information). The entries in italics denote variables determined by an experimental design, which is explained in Section 3.3.

The second part of phase II consists of a list of statements on topics related to electric 


\begin{tabular}{|c|c|c|c|}
\hline Characteristics & Your vehicle & $\begin{array}{l}\text { Renault vehicle } \\
\text { with combustion } \\
\text { engine }\end{array}$ & $\begin{array}{l}\text { Renault electric } \\
\text { vehicle }\end{array}$ \\
\hline Make & Audi & Renault & Renault \\
\hline Model & $\mathrm{A} 4$ & Laguna & Fluence \\
\hline Fuel & Gasoline & Gasoline & Electricity \\
\hline Purchase price (in $\mathrm{CHF}$ ) & 42,400 & 37,200 & 56,880 \\
\hline Incentive (in CHF) & 0 & 0 & $-1,000$ \\
\hline $\begin{array}{l}\text { Total purchase price (in } \\
\text { CHF) }\end{array}$ & 42,400 & 37,200 & 55,880 \\
\hline $\begin{array}{l}\text { OR: Monthly leasing price } \\
\text { (in CHF) }\end{array}$ & 477 & 399 & 693 \\
\hline $\begin{array}{l}\text { Maintenance costs (in } \mathrm{CHF} \\
\text { for } 30,000 \mathrm{~km} \text { ) }\end{array}$ & 850 & 850 & 425 \\
\hline $\begin{array}{l}\text { Cost in fuel/electricity for } \\
100 \mathrm{~km} \text { (in CHF) }\end{array}$ & 11.70 & 13.55 & 3.55 \\
\hline $\begin{array}{l}\text { Battery lease (in CHF per } \\
\text { month) }\end{array}$ & 0 & 0 & 125 \\
\hline
\end{tabular}

Table 1: An example of a choice situation presented to respondents with a non-Renault car in their household.

vehicles, jointly defined with Renault. For each statement, the respondent was asked to rate his agreement on a five-point Likert scale, ranging from a 'total disagreement' to a 'total agreement'.

We defined statements in relation to five themes: the importance of car design, the perception of leasing, the perception of an electric vehicle as an ecological solution, the attitude towards new technologies, and the reliability, security and use of an electric vehicle. Examples of statements are provided below:

- I give more importance to my vehicle's spaciousness or capacity to transport people and luggages than to its look.

- Leasing is an optimal contract which enables me to change my car frequently.

- I prefer driving a car with a powerful engine than a car that emits little carbon dioxide.

- I never travel without a GPS.

- The low range of the battery is a real disadvantage. 
The ratings collected on these statements provide indicators of individuals' attitudes towards the different themes. These attitudes are assumed to have an important impact on their purchase choice.

In order to analyze whether there exists heterogeneity of attitudes within the population, we performed an exploratory analysis on the answers to the opinion statements. The results show that respondents differ in their responses to opinion questions. As a first example, Figure 1(a) shows the responses to sentence 'Design is a secondary element when purchasing a car, which is above all a practical transport mode.' Two groups appear: individuals who favor the practical aspects of a car and individuals who are interested in its design. As a second example, Figure 1(b) displays the responses to statement 'I prefer to pay the total price of my car at one time to avoid having to allow a leasing budget every month.' The graph highlights differences in the perception of the lease of a car: most individuals seem to dislike it, while a substantial proportion is in favor of such a contract.

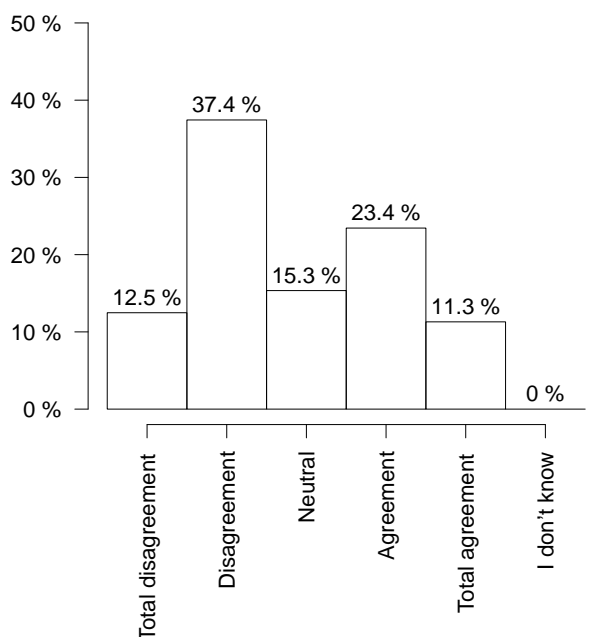

(a) Design is a secondary element when purchasing a car, which is above all a practical transport mode.

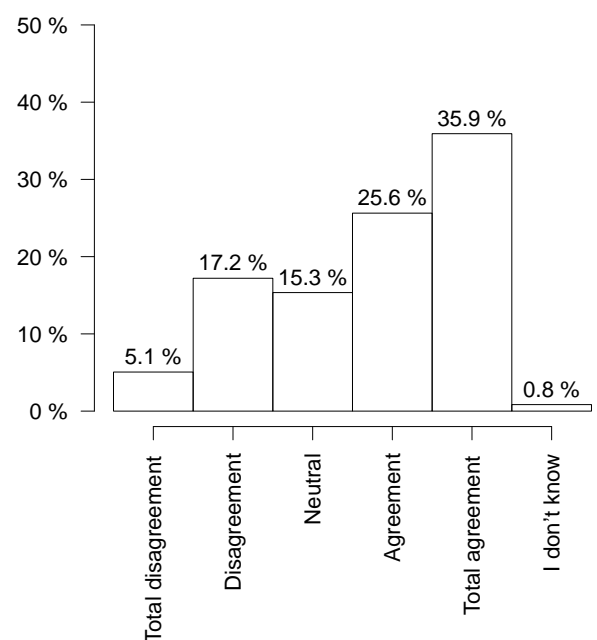

(b) I prefer to pay the total price of my car at one time to avoid having to allow a leasing budget every month.

Figure 1: Histograms of the answers to two opinion statements.

\subsection{Sampling protocol}

The sample for the survey consists of five types of respondents:

- Recent buyers, i.e. individuals who bought a new car in the last three years.

- Prospective buyers, i.e. individuals who plan to buy a new car in the next six 
months.

- Renault customers, i.e. individuals who own a Renault car.

- Future Renault customers, i.e. individuals who pre-ordered a Renault electric vehicle.

- Newsletter members, i.e. individuals who joined the Renault newsletter on electric vehicles.

We chose to sample individuals from the two first groups, since they had bought a new car recently or they intended to purchase one soon. It was thus assumed to be rather easy for them to give a realistic answer to a choice situation. In addition, the sample was completed with data bases of current and future Renault customers and newsletter members, whose addresses where provided by Renault.

The respondents in the three first groups, i.e. the recent, prospective buyers and Renault customers, were selected in order to be representative of the proportions of individuals within each language (German, French or Italian), gender (male or female) and age (18-35 years, 36-55 years or 56-74 years) category in the population of Switzerland. The target proportions for each socio-economic group, as well as the obtained ones are shown in Table 2. The differences between the target and response rates are due to self-selection.

\begin{tabular}{ll|rrr} 
Variable & Level & Population & Rate phase I & Rate phase II \\
\hline Language & & & & \\
& German & $72.5 \%$ & $67.3 \%$ & $67.8 \%$ \\
& French & $23.0 \%$ & $27.2 \%$ & $26.6 \%$ \\
& Italian & $4.5 \%$ & $5.56 \%$ & $5.56 \%$ \\
Gender & & & & \\
& Male & $49.4 \%$ & $74.0 \%$ & $74.2 \%$ \\
& Female & $50.6 \%$ & $26.0 \%$ & $25.8 \%$ \\
Age category & & & \\
& & & & \\
& 18-35 years & $33.6 \%$ & $23.0 \%$ & $21.8 \%$ \\
& 36-55 years & $41.6 \%$ & $51.8 \%$ & $52.6 \%$ \\
& 56-74 years & $24.8 \%$ & $25.2 \%$ & $25.6 \%$ \\
\hline
\end{tabular}

Table 2: Proportions of each socio-economic group (language, gender and age) in the population of Switzerland (target rates) and corresponding response rates after phase I and phase II.

Due to the small sizes of the two last groups, i.e. the future Renault customers and the newsletter members, no sampling protocol was applied to them, which implies that all 
individuals belonging to these groups were selected for the survey.

The number of responses after phase I and phase II are reported in Table 3, for each sample group.

\begin{tabular}{ll|r|rr|rr|r} 
& Group name & Sent & Phase I & Phase II & Phase I vs phase II \\
Number & Rate & Number & Rate & Rate \\
\hline 1 & Recent buyers & 3006 & 150 & $10.0 \%$ & 141 & $9.4 \%$ & $94.0 \%$ \\
2 & Prospective buyers & 151 & & 141 & & $93.4 \%$ \\
3 & Renault customers & 1000 & 145 & $14.5 \%$ & 120 & $12.0 \%$ & $82.8 \%$ \\
4 & Future Renault customers & 42 & 23 & $54.8 \%$ & 19 & $45.2 \%$ & $82.6 \%$ \\
5 & Newsletter members & 656 & 197 & $30.0 \%$ & 172 & $26.2 \%$ & $87.3 \%$ \\
\hline & Total & 4704 & 666 & $14.2 \%$ & 593 & $12.6 \%$ & $89.0 \%$
\end{tabular}

Table 3: Number of online questionnaires sent, numbers and rates of responses after phase I and phase II, and between both phases, for each sample group.

Due to self-selection, some socio-economic categories of the sample were over- or under-represented. For example, men $(74.2 \%)$ were over-represented compared to women $(25.8 \%)$. Therefore the induced bias must be corrected for the sample to reflect the real population proportions. In order to match the proportion of each socio-economic category in the Swiss population, a weight $w_{n}$ is computed for each observation $n$ in the sample, using the IPF technique. To be more precise, it reflects the representativity of observation $n$ in the population in terms of language (German, French or Italian), gender (male or female), age category (18-35 years, 36-55 years, 56-74 years) and target group (recent buyers, prospective buyers, Renault customers, future Renault customers and newsletter members).

\subsection{Experimental design}

We are interested in analyzing the respondents' sensitivity to four price-related characteristics of electric cars: the purchase price, a possible incentive from the government, the operating costs and the battery lease. Since these four variables are attributes of a hypothetical alternative, we construct an experimental design. The levels of the variables are reported in Table 4.

The number of levels for each variable of Table 4 leads to a full factorial design of size $S=3 \times 3 \times 3 \times 4=108$. Given the total number of questionnaires and in order to obtain a sufficient number of occurrences for each configuration, the size of the full factorial design is reduced to 64 . Let us note that the resulting fractional factorial design is orthogonal in 


\begin{tabular}{l|rrrr} 
Level & Purchase price $P$ & Incentive $I$ & Cost $C$ of $100 \mathrm{~km}$ & Battery lease $L$ \\
\hline 1 & $\left(P_{\text {own }}+5,000 \mathrm{CHF}\right) \cdot 0.8$ & $-0 \mathrm{CHF}$ & $1.70 \mathrm{CHF}$ & $85 \mathrm{CHF}$ \\
2 & $\left(P_{\text {own }}+5,000 \mathrm{CHF}\right) \cdot 1.0$ & $-500 \mathrm{CHF}$ & $3.55 \mathrm{CHF}$ & $105 \mathrm{CHF}$ \\
3 & $\left(P_{\text {own }}+5,000 \mathrm{CHF}\right) \cdot 1.2$ & $-1,000 \mathrm{CHF}$ & $5.40 \mathrm{CHF}$ & $125 \mathrm{CHF}$ \\
4 & - & $-5,000 \mathrm{CHF}$ & - & - \\
\hline
\end{tabular}

Table 4: Levels of the variables related to the electric vehicles which are subject to an experimental design, that is, the purchase price $P$, based on the price $P_{\text {own }}$ of the respondent's car, a possible governmental incentive $I$, the cost $C$ of driving $100 \mathrm{~km}$ and the battery lease $L$.

the main effects.

Due to the differences among the respondents of the five target groups introduced in Section 3.2, some undesired variability could occur in their answers to the choice situations. For example, members of the newsletter on electric vehicles could have a priori preferences for the electric alternative, which might not necessarily be the case for individuals who recently bought a car. This source of variability can be avoided by performing blocking. Let us note that in this procedure groups 3 and 4 were merged (current and future Renault customers) because of their similarity. More details on the construction of the blocks can be found in Glerum et al. (2011) on page 13.

Every respondent $n$ is exposed to five choice situations. For each $n$, a list of five configurations is therefore randomly selected in the table of configurations corresponding to $n$ 's target group (e.g. Table 5 for recent buyers). The probabilities of selecting each configuration are calculated using the IPF algorithm, in such a way that each level has the same asymptotic frequency of occurrence. The IPF algorithm is generally used to correct for oversampled or undersampled observations sampled from a population with respect to the real socio-demographic structure of that population. It is applied here in a different context in order to find the probabilities of selecting configurations in an experimental design of an SP survey. For example in Table 5, the price level '1.00' appears in 8 combinations out of 16 while the levels ' 0.80 ' and ' 1.20 ' appear only 4 times. Therefore the probability given by the IPF to select a combination with price ' 1.00 ' will be half the probability of other combinations.

\section{Stated preferences (SP) model}

Our assumption is that some attitudinal factors have an important impact on individuals' choices of cars. These factors can be revealed from the responses to the opinion state- 


\begin{tabular}{rrrrr}
\hline & Incentive & Price & Fuel cost of $100 \mathrm{~km}$ & Battery lease \\
\hline 1 & 0 & 0.80 & 1.70 & 85 \\
2 & 0 & 1.00 & 3.55 & 125 \\
3 & 0 & 1.00 & 5.40 & 105 \\
4 & 0 & 1.20 & 3.55 & 105 \\
5 & -500 & 0.80 & 1.70 & 125 \\
6 & -500 & 1.00 & 3.55 & 85 \\
7 & -500 & 1.00 & 5.40 & 105 \\
8 & -500 & 1.20 & 3.55 & 105 \\
9 & -1000 & 0.80 & 3.55 & 105 \\
10 & -1000 & 1.00 & 5.40 & 105 \\
11 & -1000 & 1.00 & 3.55 & 85 \\
12 & -1000 & 1.20 & 1.70 & 125 \\
13 & -5000 & 0.80 & 3.55 & 105 \\
14 & -5000 & 1.00 & 5.40 & 105 \\
15 & -5000 & 1.00 & 3.55 & 125 \\
16 & -5000 & 1.20 & 1.70 & 85 \\
\hline
\end{tabular}

Table 5: Possible four-level configurations for the respondents of group 'recent buyers'.

ments described in Section 3.1 and integrated into a discrete choice model using the HCM framework.

We developed an HCM based on the data collected from the SP survey and in this section we present its specification and estimation results. Since the model is estimated on SP data, we denote it as SP model. The HCM integrates two components: a latent variable model ( $L V M)$, which allows for the characterization of the identified attitudes by socio-economic attributes of the respondents and a logit model, which explains respondents' vehicle choices by their attitudes, socio-economic characteristics and by vehicle attributes.

\subsection{Model specification}

In this section, we present the specifications of the LVM and the logit model. 


\subsubsection{Latent variable model (LVM)}

In order to characterize the attitudes affecting individuals' choices, we first needed to identify the opinion statements measuring these attitudes and the socio-economic characteristics explaining the latter. For this purpose, we performed exploratory factor analysis. This enabled us to identify four attitudinal dimensions. Further specification testing led us to retain only two out of these four factors, associated with a more significant effect on the choice. These two factors characterize the following attitudes:

- A pro-leasing attitude, characterizing individuals in favor of leasing contracts.

- A pro-convenience attitude, characterizing individuals who prefer the spaciousness, comfort or a potential new propulsion technology of a car than its design.

As a result from the factor analyses, the pro-leasing attitude was measured by the answers to the five following psychometric indicators:

Opinion Leasing $1\left(I_{1,1}\right)$ : Leasing is an optimal contract which enables me to change my car frequently.

Opinion Leasing $2\left(I_{1,2}\right)$ : With a leasing contract I feel that the car does not belong to me completely.

Opinion Leasing $3\left(I_{1,3}\right)$ : I prefer to pay the total price of my car at one time to avoid having to allow a leasing budget every month.

Opinion Leasing $4\left(I_{1,4}\right)$ : A leasing contract is more adapted in the case of the purchase of an electric vehicle.

Opinion Leasing $5\left(I_{1,5}\right)$ : As the technology of an electric car's battery will evolve rapidly, its lease is more adapted, implying its replacement by a more efficient battery when it does not work in an optimal way anymore.

Similarly, the pro-convenience attitude was revealed from the following indicators:

Opinion convenience $1\left(I_{2,1}\right)$ : Design is a secondary element when purchasing a car, which is above all a practical transport mode.

Opinion convenience $2\left(I_{2,2}\right)$ : I give more importance to my vehicle's spaciousness or capacity to transport people and luggages than to its look. 
Opinion convenience $3\left(I_{2,3}\right)$ : I prefer having a car with a new propulsion technology to a car with a nice look.

Based on the results of the exploratory analysis, two LVMs are built for the pro-leasing attitude and the pro-convenience attitude, respectively.

LVM1: pro-leasing attitude The structural equation relative to the pro-leasing attitude $A t t L$ is specified as follows:

$$
\operatorname{AttL}=\beta_{\text {Mean1 }}+\sum_{i} \beta_{1, i} \cdot X_{1, i}+e^{\nu_{1}} \cdot \Omega_{1},
$$

where $X_{1, i}$ are socio-economic characteristics of the respondent, $\beta_{\text {Mean1 }}, \beta_{1, i}$ and $\nu_{1}$ are parameters to estimate and $\Omega_{1} \sim \mathcal{N}(0,1)$ is a random component. Coefficients $\beta_{1, i}$ and $e^{\nu_{1}}$ are shown in the first column of Table 7 and the socio-economic variables $X_{1, i}$ and the random term $\Omega_{1}$ appear in the second column. The specification of the structural equation relative to the pro-leasing attitude $A t t L$ is given by the inner product of these two columns. The third column provides a description of each variable.

Latent variable $A t t L$ is related to the five indicators $I_{1, k}$ reported above by the following measurement equations:

$$
I_{1, k}=\alpha_{1, k}+\lambda_{1, k} \cdot \operatorname{AttL}+e^{\sigma_{1, k}} \Omega_{1, k},
$$

where $\Omega_{1, k} \sim \mathcal{N}(0,1)$, for $k=1, \ldots, 5$.

LVM2: pro-convenience attitude The structural equation for the pro-convenience attitude $A t t C$ is specified in a similar way as for LVM1.

$$
\mathrm{AttC}=\beta_{\text {Mean2 }}+\sum_{i} \beta_{2, i} \cdot X_{2, i}+e^{\nu_{2}} \cdot \Omega_{2},
$$

where $X_{2, i}$ are socio-economic characteristics of the respondent, $\beta_{\mathrm{Mean} 2}, \beta_{2, i}$ and $\nu_{2}$ are coefficients to estimate and $\Omega_{2} \sim \mathcal{N}(0,1)$. Coefficients $\beta_{2, i}$ and $e^{\nu_{2}}$ are shown in the first column of Table 9 and the socio-economic variables $X_{2, i}$ and the random term $\Omega_{2}$ appear in the second column. The specification of the structural equation is given by the inner product of the two first columns of Table 9. The third column provides a description of each variable.

The measurement equations relate the indicators $I_{2, k}$ associated with the above statements to the latent variable $A t t C$. They are specified as follows:

$$
I_{2, k}=\alpha_{2, k}+\lambda_{2, k} \cdot \operatorname{AttC}+e^{\sigma_{2, k}} \Omega_{2, k},
$$

where $\Omega_{2, k} \sim \mathcal{N}(0,1)$, for $k=1,2,3$. 


\subsubsection{Logit model}

The respondents are facing a vehicle choice among their own current car, a possible analogous gasoline or diesel Renault car and a similar electric Renault car. As described in Section 3.1, Renault owners were only shown two cars while owners of cars from competitors were shown three vehicles, leading to the two following choice sets:

$$
C_{m}^{\text {Renault }}=\{\text { Renault }- \text { gasoline }(\mathrm{RG}), \text { Renault }- \text { electric }(\mathrm{RE})\},
$$

where individual $m$ owns a Renault car, and

$C_{n}^{\text {non-Renault }}=\{$ Competitors - gasoline $(\mathrm{CG})$, Renault - gasoline $(\mathrm{RG})$, Renault - electric $(\mathrm{RE})\}$, where individual $n$ owns a non-Renault car.

Different specifications were tested for the logit model and the one that was retained is shown in Table 6 on page 36 . The deterministic parts $V_{\mathrm{CG}}, V_{\mathrm{RG}}$ and $V_{\mathrm{RE}}$ of the utility functions of the three alternatives are given by the inner product between the left-hand column 'Utilities' and columns 'CG', 'RG' and 'RE', respectively. The model contains both linear and non-linear terms. To be precise, non-linear expressions are considered in order to constrain the coefficients of some of the price-related variables to be negative. The randomness due to the introduction of latent variables in the model could otherwise lead to non-negative price coefficients for part of the sample. The latent variables are indeed introduced as interaction terms with some of the price-related variables. With these interaction terms, we capture the differences in the sensitivity to variations in the purchase price for individuals with different levels of pro-convenience, and the differences in the sensitivity to variations in the monthly rent of the battery for pro- and anti-leasing individuals. This final model is moreover a result of a market segmentation by target group (TG). It incorporates the following variables:

- The purchase prices price $_{C G}$, price $_{R G}$ and price $_{R E}$ relative to alternatives CG, RG and RE, in CHF.

- The operating costs for gasoline/diesel cars for which the cost of driving $100 \mathrm{~km}$ is less than $12 \mathrm{CHF}$ :

$$
\begin{aligned}
& \text { UseCostGasoline }_{\mathrm{CG}}=\min \left(\operatorname{Cost}_{100_{\mathrm{CG}}}, 12\right) \\
& \text { UseCostGasoline }_{\mathrm{RG}}=\min \left(\operatorname{Cost} 100_{\mathrm{RG}}, 12\right)
\end{aligned}
$$


- The operating costs for the electric car, where UseCostElecHigh denotes the highest level (5.40 CHF per $100 \mathrm{~km}$ ) of the experimental design and UseCostElecMed denotes the medium level (3.55 CHF per $100 \mathrm{~km})$.

- The monthly lease of the battery Battery, in CHF.

- The possible governmental incentive, where IncentiveHigh is an indicator of the highest level of incentive $(-5,000 \mathrm{CHF})$, IncentiveMed of the medium level $(-1,000 \mathrm{CHF})$ and IncentiveLow of the lowest level ( $-500 \mathrm{CHF})$.

- Socio-economic characteristics, including commuters by public transportation $(P T)$, families with children (SitFam), households whose monthly income is higher than 8, 000 CHF (Income), number of cars in the household (NbCars), French-speaking individuals (French) - opposed to German- and Italian-speaking individuals, respondents' age (Age), recent and prospective buyers (TG12), Renault customers (TG3), future Renault customers and newsletter members (TG45), recent buyers, prospective buyers, future Renault customers and newsletter members (TG1245).

- Attitudes AttL and AttC, defined by the LVMs.

- Alternative specific constants $A S C_{\mathrm{CG}}$ and $A S C_{\mathrm{RG}}$.

\subsection{Model estimation}

We performed a simultaneous estimation of the HCM. The model parameters we estimated by maximum likelihood using the extended version of the software Biogeme (Bierlaire and Fetiarison, 2009). In the case where the respondent owns a Renault car, alternative RG is made unavailable and it is not included in the computation of the likelihood function. The likelihood is given by the following expression:

$$
\begin{gathered}
L=\int_{\mathrm{AttL}} \int_{\mathrm{AttC}} P(y \mid X, \operatorname{AttL}, \operatorname{AttC} ; \beta) f\left(\operatorname{AttL} \mid X_{1} ; \beta_{1}, \nu_{1}\right) f\left(\operatorname{AttC} \mid X_{2} ; \beta_{2}, \nu_{2}\right) \\
\cdot f\left(I_{1} \mid \operatorname{AttL} ; \alpha_{1}, \lambda_{1}, \sigma_{1}\right) f\left(I_{2} \mid \operatorname{AttC} ; \alpha_{2}, \lambda_{2}, \sigma_{2}\right) d \operatorname{AttL} d \mathrm{AttC}
\end{gathered}
$$

where $X, X_{1}$ and $X_{2}$ are vectors of socio-economic attributes of the respondent, $\beta$ is a vector of parameters related to the structural equation of the choice model, $\beta_{j}$ are vectors of parameters relative to the structural equations of the LVMs, with $j=1,2, I_{j}=$ $\left(I_{j, 1}, \ldots, I_{j, K}\right)$ are vector of indicators relative to LVM $j$, parameters $\alpha_{j}=\left(\alpha_{j, 1}, \ldots, \alpha_{j, K_{j}}\right)$, $\lambda_{j}=\left(\lambda_{j, 1}, \ldots, \lambda_{j, K_{j}}\right)$ and $\sigma_{j}=\left(\sigma_{j, 1}, \ldots, \sigma_{j, K_{j}}\right)$ are vectors of parameters relative to the $K_{j}$ measurement equations of $\operatorname{LVM} j$. 
Variable $y$ is a matrix of individual choice indicators $y_{i n}$ :

$$
y_{i n}= \begin{cases}1 & \text { if individual } n \text { selects alternative } i \\ 0 & \text { otherwise }\end{cases}
$$

In Equation (3), the expressions $f\left(I_{j} \mid X^{*} ; \alpha_{j}, \lambda_{j}, \sigma_{j}\right)$, with $j=1,2$ and $X^{*} \in\{A t t L, A t t C\}$, are the products of the individual density functions of indicators $I_{j, k}$ :

$$
f\left(I_{j} \mid X^{*} ; \alpha_{j}, \lambda_{j}, \sigma_{j}\right)=\prod_{k=1}^{K_{j}} f\left(I_{j, k} \mid X^{*} ; \alpha_{j, k}, \lambda_{j, k}, \sigma_{j, k}\right),
$$

Though all components of the HCM are estimated simultaneously, we present the parameter estimates of each model component separately. The estimation results of LVM1 can be seen in Tables 7 and 8 and those of LVM2 in Tables 9 and 10. Finally, the estimates of the logit model are displayed in Table 11 on page 37.

The estimated parameters of the structural equation of LVM1 are reported in column 'Parameter estimate' of Table 7 and the corresponding $t$-test values appear in column ' $t$ test'. Except parameter $\beta_{\text {Income8+, }}$ all estimates are significant and characterize attitude $A t t L$ in a meaningful way.

The parameters relative to the measurement equations are presented in Table 8. Parameter $\alpha_{1,1}$ has been normalized to 0 and parameter $\lambda_{1,1}$ to 1 . The signs of $\lambda_{1, k}$, for $k=2, \ldots, 5$, are consistent with the expectations on the impact the pro-leasing attitude has on the responses to the indicators $I_{1, k}$. For example, indicators $I_{1,2}$ and $I_{1,3}$ express an anti-leasing attitude and the signs of $\lambda_{1,2}$ and $\lambda_{1,3}$ are negative. 


\begin{tabular}{|c|c|c|c|c|}
\hline Coefficient & Variable & Variable description & $\begin{array}{l}\text { Parameter } \\
\text { estimate }\end{array}$ & $t$-test \\
\hline$\beta_{\text {Mean1 }}$ & 1 & - & 2.92 & 31.38 \\
\hline$\beta_{\text {Children }}$ & $X_{\text {Children }}$ & $\begin{array}{l}1 \text { if the respondent has children and } 0 \\
\text { otherwise }\end{array}$ & 0.238 & 3.43 \\
\hline$\beta_{\text {Age1 }}$ & $X_{30<\text { Age }<50}$ & $\begin{array}{l}1 \text { if the respondent's age is between } 30 \\
\text { and } 50 \text { years and } 0 \text { otherwise }\end{array}$ & -0.135 & -3.24 \\
\hline$\beta_{\text {Couples }}$ & $X_{\text {Couples }}$ & $\begin{array}{l}1 \text { if the respondent's household is be- } \\
\text { longs to the category of couples with } \\
\text { children and } 0 \text { otherwise }\end{array}$ & -0.215 & -3.16 \\
\hline$\beta_{\text {Shared }}$ & $X_{\text {Shared }}$ & $\begin{array}{l}1 \text { if the respondent is living in a shared } \\
\text { housing and } 0 \text { otherwise }\end{array}$ & -0.502 & -3.03 \\
\hline$\beta_{\text {Retired1 }}$ & $X_{\text {Retired }}$ & $\begin{array}{l}1 \text { if the respondent is retired and } 0 \text { oth- } \\
\text { erwise }\end{array}$ & -0.389 & -5.42 \\
\hline$\beta_{\text {Smartphone }}$ & $X_{\text {Smartphone }}$ & $\begin{array}{l}1 \text { if the respondent has a smartphone } \\
\text { and } 0 \text { otherwise }\end{array}$ & 0.264 & 6.47 \\
\hline$\beta_{\text {French }}$ & $X_{\text {French }}$ & $\begin{array}{l}1 \text { if the respondent's language is French } \\
\text { and } 0 \text { otherwise }\end{array}$ & -0.363 & -4.10 \\
\hline$\beta_{\text {German }}$ & $X_{\text {German }}$ & $\begin{array}{l}1 \text { if the respondent's language is Ger- } \\
\text { man and } 0 \text { otherwise }\end{array}$ & -0.560 & -6.63 \\
\hline$\beta_{\text {University }}$ & $X_{\text {University }}$ & $\begin{array}{l}1 \text { if the respondent has a university de- } \\
\text { gree and } 0 \text { otherwise }\end{array}$ & -0.144 & -2.80 \\
\hline$\beta_{\text {Income4-6 }}$ & $X_{\text {Income4-6 }}$ & $\begin{array}{l}1 \text { if the respondent's household has } \\
\text { a monthly revenue between } 4,000 \text { and } \\
6,000 \mathrm{CHF} \text { and } 0 \text { otherwise }\end{array}$ & 0.158 & 2.21 \\
\hline$\beta_{\text {Income6-8 }}$ & $X_{\text {Income6-8 }}$ & $\begin{array}{l}1 \text { if the respondent's household has } \\
\text { a monthly revenue between } 6,000 \text { and } \\
8,000 \mathrm{CHF} \text { and } 0 \text { otherwise }\end{array}$ & 0.166 & 2.72 \\
\hline$\beta_{\text {Income8+ }}$ & $X_{\text {Income8+ }}$ & $\begin{array}{l}1 \text { if the respondent's household has a } \\
\text { monthly revenue above } 8,000 \mathrm{CHF} \text { and } \\
0 \text { otherwise }\end{array}$ & $-0.0107^{* *}$ & -0.21 \\
\hline$e^{\nu_{1}}$ & $\Omega_{1}$ & Random variable $\mathcal{N}(0,1)$ & -0.0974 & -4.12 \\
\hline
\end{tabular}

Table 7: Specification table and estimation results of LVM1 (** Statistical significance $<90 \%$, * Statistical significance $<95 \%)$. 


\begin{tabular}{l||cc||cc||lc}
\hline Indicator & $\lambda_{1, k}$ & $t$-test & $\alpha_{1, k}$ & $t$-test & $\sigma_{1, k}$ & $t$-test \\
\hline Opinion leasing 1 & 1 & - & 0 & - & -0.222 & -11.12 \\
Opinion leasing 2 & -0.679 & -24.40 & 5.40 & 73.71 & $-0.0113^{* *}$ & -0.74 \\
Opinion leasing 3 & -1.04 & -33.83 & 6.27 & 78.27 & -0.213 & -9.92 \\
Opinion leasing 4 & 0.809 & 33.03 & 0.960 & 14.88 & -0.268 & -14.96 \\
Opinion leasing 5 & 0.547 & 23.96 & 2.04 & 33.79 & -0.151 & -10.09 \\
\hline
\end{tabular}

Table 8: Estimates of the parameters of the measurement equations of LVM1, with values of the $t$-test $(* *$ Statistical significance $<90 \%, *$ Statistical significance $<95 \%$ ).

The estimation results for the structural equation of LVM2 are reported in column 'Parameter estimate' of Table 9 . The correponding $t$-test can be read in column ' $t$-test'. All parameters except $\nu_{2}$ are significant and a meaningful characterization of the individuals with a pro-convenience attitude can be inferred.

The parameter estimates of the measurement equations of LVM2 are reported in Table 10. Parameter $\alpha_{2,1}$ has been normalized to 0 and parameter $\lambda_{2,1}$ to 1 . The signs of $\lambda_{2, k}$, for $k=2,3$, are consistent with expectations on the effect of $A t t C$ on each indicator $I_{2, k}$.

\begin{tabular}{|c|c|c|c|c|}
\hline Coefficient & Variable & Variable description & $\begin{array}{l}\text { Parameter } \\
\text { estimate }\end{array}$ & $t$-test \\
\hline$\beta_{\text {Mean2 }}$ & 1 & - & 2.28 & 32.73 \\
\hline$\beta_{\text {Male }}$ & $X_{\text {Male }}$ & $\begin{array}{l}1 \text { if the respondent is male and } 0 \text { if the } \\
\text { respondent is female }\end{array}$ & -0.171 & -3.32 \\
\hline$\beta_{\text {NbPeople }}$ & NbPeople & $\begin{array}{l}\text { Number of members in the respondent's } \\
\text { household }\end{array}$ & 0.131 & 6.91 \\
\hline$\beta_{\text {Age } 2}$ & $X_{\text {Age }>45} \cdot$ Age & $\begin{array}{l}1 \text { if the respondent is older than } 45 \text { and } \\
0 \text { otherwise; age of the respondent }\end{array}$ & 0.00604 & 6.89 \\
\hline$\beta_{\text {Retired2 }}$ & $X_{\text {Retired }}$ & $\begin{array}{l}1 \text { if the respondent is retired and } 0 \text { oth- } \\
\text { erwise }\end{array}$ & 0.418 & 5.03 \\
\hline$\beta_{\text {Homeowner }}$ & $X_{\text {Homeowner }}$ & $\begin{array}{l}1 \text { if the respondent is a homeowner and } \\
0 \text { otherwise }\end{array}$ & 0.161 & 3.36 \\
\hline$e^{\nu_{2}}$ & $\Omega_{2}$ & Random variable $\mathcal{N}(0,1)$ & $0.0378^{* *}$ & 1.58 \\
\hline
\end{tabular}

Table 9: Specification table and estimation results of LVM2 (** Statistical significance $<90 \%$,

* Statistical significance < $95 \%$ ). 


\begin{tabular}{l||cc||cc||cc}
\hline Indicator & $\lambda_{2, k}$ & $t$-test & $\alpha_{2, k}$ & $t$-test & $\sigma_{2, k}$ & $t$-test \\
\hline Opinion convenience 1 & 1 & - & 0 & - & -0.527 & -9.57 \\
Opinion convenience 2 & 0.670 & 26.12 & 1.55 & 20.82 & -0.220 & -11.60 \\
Opinion convenience 3 & 0.509 & 23.33 & 1.91 & 29.87 & -0.170 & -11.01 \\
\hline
\end{tabular}

Table 10: Estimates of the parameters of the measurement equations of LVM2, with values of the $t$-test $(* *$ Statistical significance $<90 \%, *$ Statistical significance $<95 \%$ ).

The estimates of the parameters of the logit model are reported in Table 11 on page 37. The signs of the significant estimates are consistent with expectations. For non-significant parameters the sign has no importance. We nevertheless decided to keep these parameters in the model.

From the estimated model parameters the following important conclusions can be drawn:

- The purchase price of any vehicle type has a negative impact on its utility function, due to the imposed constraint.

The estimate of the parameter $\beta_{\text {AttC }}$ relative to attitude $A t t C$ is negative and significant. This means that an increase in the purchase price of any car will penalize its choice more for individuals interested in the design of a car than for individuals who favor its practical aspects. The latter might be less sensitive to price changes since the pro-convenience attitude is revealed from elements such as the interest for spaciousness or technology.

- By construction the battery lease Battery has negative effect on the electric vehicle choice. Both parameters $\beta_{\text {Battery }}$ and $\beta_{\text {AttL }}$ are significant. The parameter relative to the pro-leasing variable $A t t L$ is negative and hence individuals with a positive attitude towards leasing will be less affected by a change in the monthly battery rent than individuals who dislike leasing. Intuitively, individuals who are already not in favor of leasing their car are more sensitive to price changes in the lease of one of the car's components.

We report the final values of log-likelihood and $\bar{\rho}^{2}$ in order to provide an indication on the models' fits. The $\bar{\rho}^{2}$ indicator is calculated as follows:

$$
\bar{\rho}^{2}=1-\frac{\mathcal{L}(\hat{\beta})-Q}{\mathcal{L}(0)}
$$


where $\hat{\beta}$ is a vector of the estimated parameters, $\mathcal{L}(\hat{\beta})$ is the corresponding log-likelihood, $Q$ is the number of parameters, and $\mathcal{L}(0)$ is the null log-likelihood. The log-likelihood values are computed for both LVMs and the DCM part of the HCM. The values for the null log-likelihood are obtained from the estimation of an HCM where only parameters $\sigma_{j, k}$ are estimated and all other parameters are set to 0.

In Table 12, we report the number of parameters, the null log-likelihoods, the final log-likelihoods and $\bar{\rho}^{2}$ values of LVM1, LVM2 and the DCM part of the HCM. The sample contains 2,965 observations resulting from the answers of 593 individuals.

\begin{tabular}{l|rrrr} 
Model & $Q$ & $\mathcal{L}(0)$ & $\mathcal{L}(\hat{\beta})$ & $\bar{\rho}^{2}$ \\
\hline LVM1 & 27 & -39348 & -20982 & 0.47 \\
LVM2 & 14 & -23496 & -12379 & 0.47 \\
DCM & 38 & -3556 & -2215 & 0.37 \\
\hline
\end{tabular}

Table 12: Number of parameters, null log-likelihoods, final log-likelihoods and $\bar{\rho}^{2}$.

\subsection{Validation}

In order to validate the SP model, we randomly split the sample into two parts: the first part contains $80 \%$ of the observations of the original data set and the second part contains the remaining $20 \%$ of the observations. We then proceed as follows:

1. We first re-estimate the parameters of the models on the $80 \%$ of the data.

2. We apply the estimated model on the remaining $20 \%$.

A histogram of the choice probabilities predicted by the SP model on the $20 \%$ of the data set is shown in Figure 2(b). By choice probability, we denote the probability given by the model that a respondent chooses the alternative that was actually chosen when performing the SP experiment. Therefore, in the histogram of Figure 2(b), a majority of the choice probabilities on the right of the graph indicates that the model predicts well the preferences individuals actually stated. Figures 2(a) and 2(c) show histograms of the confidence bounds of the predicted choice probabilities. To be more precise, Figure 2(a) shows the histogram of the $5 \%$ confidence bounds of the choice probabilities of the SP model and Figure 2(c) presents the histogram of the $95 \%$ confidence bounds. Such confidence bounds were generated by simulation, based on the values of the standard errors of the parameters. The graphs can be interpreted as follows: the more similar the histograms 
of the confidence bounds are to the histogram of choice probabilities, the more robust the model performs in terms of prediction.

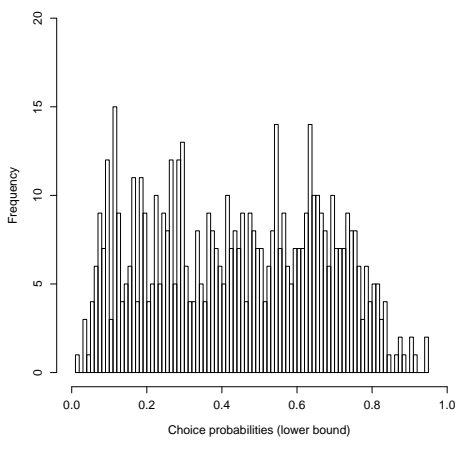

(a) Lower confidence bound (5\%)

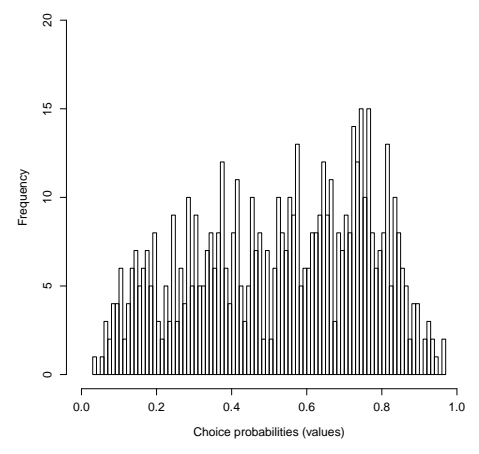

(b) Value

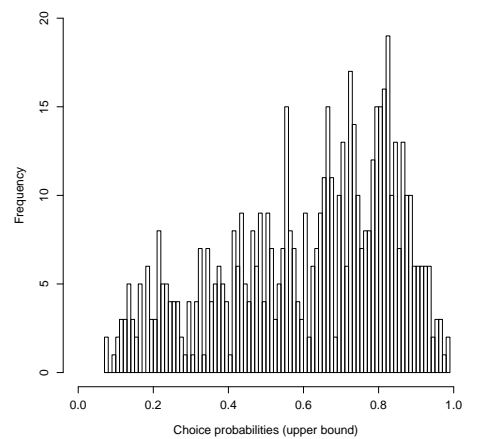

(c) Upper confidence bound (95\%)

Figure 2: Histograms of the choice probabilities for the HCM.

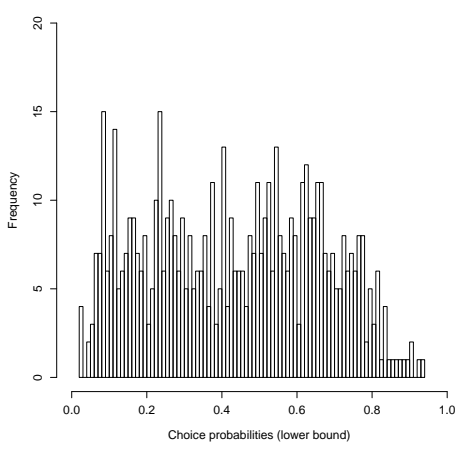

(a) Lower confidence bound $(5 \%)$

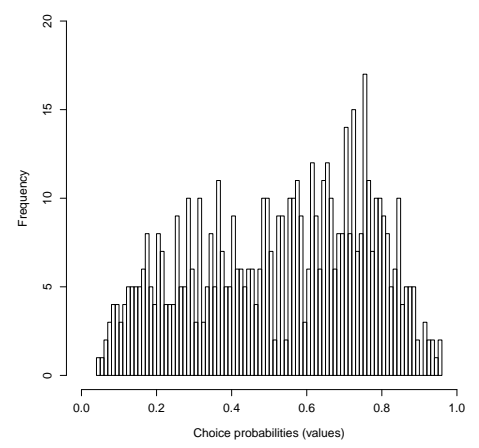

(b) Value

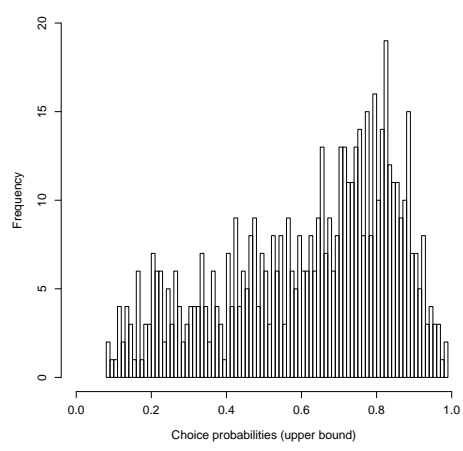

(c) Upper confidence bound (95\%)

Figure 3: Histograms of the choice probabilities for the logit model.

In order to compare the performance of the HCM in terms of prediction with the performance of a logit model without latent variables, we also plotted the histogram of the choice probabilities for this simpler model in Figure 3(b). Similarly as for the HCM, we also plot the histograms of the $5 \%$ and $95 \%$ confidence bounds (see Figures $3(\mathrm{a})$ and $3(\mathrm{c}))$.

Figures 2(b) and 3(b) graphically show that both the HCM and the logit model have a good prediction power, since a high number of choice probabilities have a value above 0.5 and are therefore concentrated on the right of the graphs. Table 13 shows a more quantitative evidence of this result by displaying the proportion of choice probabilities greater than three thresholds: 0.5, 0.7 and 0.9. Both models show an equivalently good 
prediction power, since the percentage of choice probabilities above each threshold are similar.

\begin{tabular}{r|rr} 
Threshold & Logit model & HCM \\
\hline 0.5 & $56.7 \%$ & $56.7 \%$ \\
0.7 & $29.7 \%$ & $30.2 \%$ \\
0.9 & $1.7 \%$ & $1.7 \%$ \\
\hline
\end{tabular}

Table 13: Proportions of choice probabilities higher than $0.5,0.7$ and 0.9 both for the logit model and the HCM.

From Figures 2 and 3, it is not exactly clear whether the HCM predicts more acurately the choice probabilities than the logit model, since the histograms of the confidence bounds are rather close to the histogram of the choice probabilities in both cases. In order to investigate this aspect quantitatively, we report the average values of the $5 \%$ and $95 \%$ confidence bounds of the choice probabilities (see Table 14). The HCM give slightly more accurate choice probabilities, since the difference between the average confidence bounds is $17.3 \%$ instead of $18.5 \%$ for the logit model.

\begin{tabular}{r|rr} 
& Logit model & HCM \\
\hline Average choice probability & $52.8 \%$ & $52.8 \%$ \\
Average 5\% confidence bound & $43.4 \%$ & $44.0 \%$ \\
Average 95\% confidence bound & $61.9 \%$ & $61.3 \%$ \\
\hline
\end{tabular}

Table 14: Average choice probabilities predicted by the logit model and the HCM, with average lower $(5 \%)$ and upper (95\%) bounds.

\section{Choice model for forecasting}

We aim at obtaining an operational model which can be used to predict the future market shares of the three car alternatives. Due to the fact that we are using SP data, several corrections need to be applied on the SP model such that it reflects the real market situation (Daly and Rohr, 1998). They are explained in this section. We denote the model resulting from these modifications as choice model for forecasting. 


\subsection{Imputation of an alternative for competitors when the respondent owns a Renault car}

An assumption for the use of DCMs is that the list of alternatives contained in the choice set of each respondent must be exhaustive. In the choice situation data collected from the questionnaire, owners of Renault cars only have the choice between two Renault models. In a real-world situation, Renault car owners would also have the option to purchase a car from a competitive brand, which the SP choice situation cannot allow.

For forecasting, we impute an alternative CG for each observation $n$ where the respondent owned a Renault car, in order to account for the fact that Renault car owners also consider vehicles from competitors when they are considering buying a new car. We construct its deterministic utility $V_{\mathrm{CG}}$ by aggregating market information about competitors' cars in the current market. More specifically, market data on the purchase prices and car consumptions are used. Such information comes from a database provided by Renault.

The utility of the aggregate alternative is obtained by the expected maximum utility (e.g. Ben-Akiva et al., 1984; Ben-Akiva and Lerman, 1985):

$$
V_{\mathrm{CG}}=E\left[\max _{\ell \in L} U_{\ell n}\right]
$$

where $L$ represents the set of all non-Renault cars in the same market segment as the Renault car proposed in the choice situation relative to observation $n$ and $U_{\ell n}$ is the utility relative to a car $\ell$ in that set. The exact formula is reported below:

$$
\begin{aligned}
U_{\ell n} & =A S C_{\mathrm{CG}}+\sum_{s \in S_{n}} \beta_{s} \cdot x_{s}+\exp \left(\beta_{\text {price }_{\mathrm{CG}}}+\beta_{\mathrm{AttC}} \cdot \mathrm{AttC}_{n}\right) \cdot \text { price }_{\ell} \\
& +\beta_{\text {UseCostGasoline }} \cdot \min \left(\operatorname{Cost} 100_{\ell}, 12\right)+\varepsilon_{\ell n}
\end{aligned}
$$

where $S_{n}$ is the set of socio-economic characteristics of the decision maker of observation $n$, price $e_{\ell}$ is the price of car $\ell, \operatorname{Cost}_{100}$ is the cost of driving $100 \mathrm{~km}$ with car $\ell$ and $\varepsilon_{\ell n} \sim E V(0,1)$.

Due to the complexity of the model, the expected maximum utility $E\left[\max _{\ell \in L} U_{\ell n}\right]$ has no closed form. Therefore it is computed by simulation.

\subsection{Correction of the constants}

As we are using SP data, the sample proportions do not reflect the actual market. As discussed by Cherchi and Ortúzar (2006) among others, the estimated constants (ASCs) must be corrected to reflect the targeted market. In our case, $A S C_{\mathrm{CG}}$ and $A S C_{\mathrm{RG}}$ of 
Table 11 on page 37 have to be corrected using real market data, such that the market shares obtained from the model reflect the Swiss market shares. In particular, we want the market shares which were predicted by the model to verify the two following properties:

- The current ratio between the market shares of Renault and its competitors should be preserved. The market shares are given by the proportion of new vehicles sold in 2010 for Renault (6.26\%) and its competitors (93.74\%).

- The market share of the electric alternative is obtained by using both acceptance rates of the electric alternative in the SP questionnaire and Swiss market data. It is indeed assumed that the response rates to the questionnaire would represent the state of the market if electric vehicles were released at the time of the study.

We partition the data between individuals owning Renault cars and individuals owning competitors' cars. For each segment, we count the weighted frequency of choice of the electric car alternative in the questionnaire, that is

$$
F_{\mathrm{RG}}=\frac{\sum_{n=1}^{N} w_{n} \delta_{n}^{\mathrm{RE}} \delta_{n}^{\mathrm{RG}}}{\sum_{n=1}^{N} w_{n} \delta_{n}^{\mathrm{RG}}},
$$

for Renault owners, and

$$
F_{\mathrm{CG}}=\frac{\sum_{n=1}^{N} w_{n} \delta_{n}^{\mathrm{RE}} \delta_{n}^{\mathrm{CG}}}{\sum_{n=1}^{N} w_{n} \delta_{n}^{\mathrm{CG}}},
$$

for non Renault owners. In the formulas, $N$ is the total number of observations, $w_{n}$ is the sample weight described in Section $3.2, \delta_{n}^{\mathrm{RE}}$ is 1 if the electric vehicle has been chosen in observation $n$, 0 otherwise, $\delta_{n}^{\mathrm{RG}}$ is 1 if observation $n$ corresponds to a Renault owner, 0 otherwise, and $\delta_{n}^{\mathrm{CG}}=1-\delta_{n}^{\mathrm{RG}}$. The assumed market share for the electric vehicle is therefore given by:

$$
\widehat{\mathrm{MS}}(\mathrm{RE})=F_{\mathrm{RG}} \mathrm{MS}(\mathrm{RG})+F_{\mathrm{CG}} \mathrm{MS}(\mathrm{CG})
$$

where $\mathrm{MS}(\mathrm{RG})$ is the observed market share of Renault vehicles $(6.26 \%)$, and $\mathrm{MS}(\mathrm{CG})=$ $1-\mathrm{MS}(\mathrm{RG})$ is the observed market share of non Renault vehicles (93.74\%).

\section{$6 \quad$ Forecasting}

Recent applications of HCM focus generally more on model estimation than on model application, but one of the major interests of such models is their capability to be used to forecast the market shares of the alternatives. This motivates the comprehensive analysis of demand for electric cars we are presenting in this section. We first present the sample 
used for forecasting. Second, we analyze successively (i) the market shares of the three car alternatives and the average revenue per individual under several pricing scenarios, (ii) the elasticity of the demand for the electric alternative and (iii) the willingness to pay relative to the decrease of the monthly battery rent.

\subsection{Forecasting sample}

In order to predict the market shares for the different alternatives, we need to apply the demand model on a data set which reflects the current car market. The forecasting sample used for this purpose is made of a synthetic population of individuals with their current car holdings. We construct it by considering all individuals who replied to the entire SP survey and by taking each car they reported in phase I.

The socio-economic information reported by the respondents is kept in the forecasting sample. It is assumed to be representative of the population structure, except for the variables of language, gender, age category and target group. For these variables, differences with the real proportions occur and the induced bias in the computation of demand indicators can be corrected by using the weights $w_{n}$ introduced in Section 3.2.

The attributes of the respondents' cars in the forecasting sample are the ones reported in phase I. If the respondent owns a Renault car, the attributes for the gasoline car from a competitive brand are computed using the aggregate alternative $E\left[\max _{\ell \in L} U_{\ell n}\right]$ introduced in Section 5.1. If he owns a car from competitors, the attributes for the Renault car are obtained from the database of cars currently on the market.

Some assumptions were made regarding the characteristics of the electric vehicle:

- The purchase price is set to the price of Fluence Z.E. (averaged over the models which are released): 31,350 CHF.

- The costs of driving $100 \mathrm{~km}$ are assumed to be equal to the middle level specified in the experimental design, that is $3.55 \mathrm{CHF}$.

- The monthly cost of leasing the battery is set to the leasing price of Fluence Z.E.: 105 CHF per month.

- The governmental incentive is set to $0 \mathrm{CHF}$, as such funding is currently not available in Switzerland.

This forecasting sample corresponds to a 'base case' scenario, where the characteristics of the electric car are assumed to reflect the real market if the electric vehicles are released 
at present. In Section 6.2.1 we evaluate alternative scenarios by simulating increases and decreases in the price of the electric car.

\subsection{Indicators}

This section focuses on analyzing demand indicators on the forecasting sample, in order to evaluate the potential demand for electric vehicles.

\subsubsection{Market shares}

The market share of each car alternative is given by the sum over all respondents $N$ of the probability of choosing that particular alternative $P_{n}(i)$, where $i \in\{\mathrm{CG}, \mathrm{RG}, \mathrm{RE}\}$. For all three alternatives, the markets shares are given by the following expressions:

$$
\begin{aligned}
& \mathrm{MS}(\mathrm{CG})=\sum_{n=1}^{N} w_{n} \cdot P_{n}(\mathrm{CG})=68.3 \% \\
& \mathrm{MS}(\mathrm{RG})=\sum_{n=1}^{N} w_{n} \cdot P_{n}(\mathrm{RG})=4.6 \% \\
& \mathrm{MS}(\mathrm{RE})=\sum_{n=1}^{N} w_{n} \cdot P_{n}(\mathrm{RE})=27.1 \%
\end{aligned}
$$

The market shares are obtained by weighting each probability $P_{n}(i)$ by the sample weight $w_{n}$. The percentages reported above result from the application of the choice model for forecasting on the forecasting sample.

An interesting indicator of demand is the average revenue $R$ of an electric vehicle per individual. It is given as follows:

$$
R=\sum_{n=1}^{N} w_{n} \cdot P_{n}(\mathrm{RE}) \cdot \text { price }_{\mathrm{RE}}=8,509 \mathrm{CHF}
$$

Similarly as for the market shares, the value for the average revenue is obtained from the application of the choice model for forecasting on the forecasting sample.

Figure 4 shows the evolution of the market shares when the purchase price of the electric car is increased or decreased. The market share of $27.1 \%$ is retrieved for the purchase price of 31,350 CHF for the electric car. As expected a decrease in the price of the electric car leads to an increase in its market share. If this price decreases down to about 7,000 CHF, the market share of the electric car can become higher than the one of classical gasoline and diesel cars from competitors of Renault.

The demand scenario also demonstrates that the average revenue per individual reaches its maximum $(\sim 8,500 \mathrm{CHF})$ for a price between 30,000 and 35,000 CHF. This price approximately corresponds to the price of the car model Fluence. 


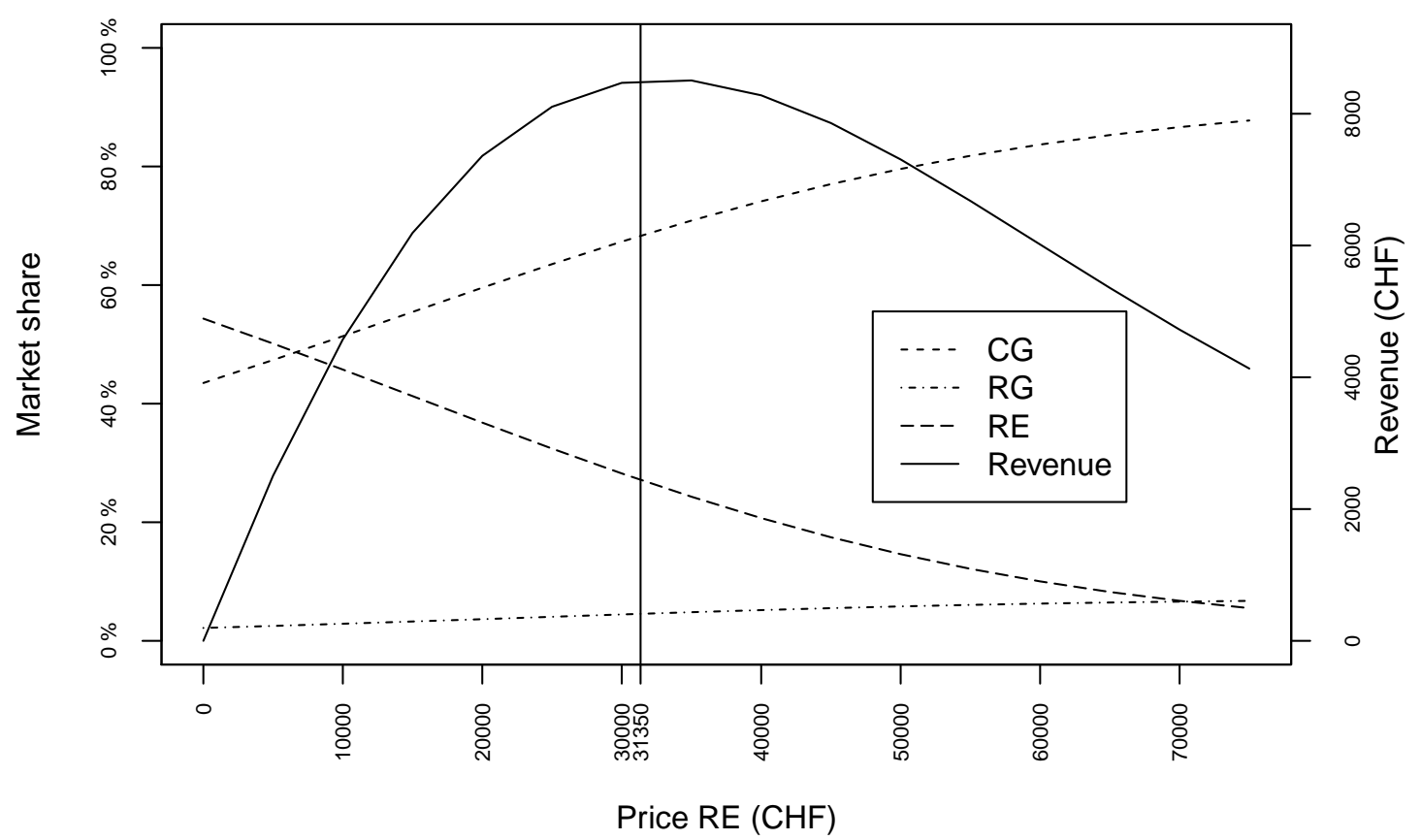

Figure 4: Market shares of competitive gasoline cars, Renault gasoline cars and Renault electric cars, for a range of prices from $0 \mathrm{CHF}$ to $75,000 \mathrm{CHF}$, and average revenue per individual.

\subsubsection{Demand elasticity for electric vehicles}

In order to understand how sensitive the demand for electric vehicles is with respect to variations in its purchase price, we report the price elasticity of demand for this alternative. This indicator is computed according to Formula (5):

$$
E_{\mathrm{price}_{\mathrm{RE}}}^{\mathrm{RE}}=\frac{\sum_{n=1}^{N} w_{n} P_{n}(\mathrm{RE}) E_{\mathrm{price}}^{\mathrm{RE}, n}}{\sum_{n=1}^{N} w_{n} P_{n}(\mathrm{RE})},
$$

where $w_{n}$ is the sample weight defined in Section 3.2 for individual $n$ and $P_{n}(\mathrm{RE})$ is the probability that individual $n$ chooses the electric alternative. This elasticity is the result of the aggregation of the $N$ individual price elasticities $E_{\text {price }_{\mathrm{RE}, n}}^{\mathrm{RE}}$, which are computed according to Expression (6):

$$
E_{\mathrm{price}}^{\mathrm{RE}, n}=\frac{\partial P_{n}(\mathrm{RE})}{\partial \operatorname{price}_{\mathrm{RE}, n}} \frac{\operatorname{price}_{\mathrm{RE}, n}}{P_{n}(\mathrm{RE})},
$$

where price $_{\mathrm{RE}, n}$ is the price of the electric vehicle for individual $n$. The individual price elasticities were simulated using Biogeme and an aggregate value of -0.92 was subsequently obtained by the application of Formula (5). Since this value is close to 1, we can conclude that the demand for electric vehicles is nearly elastic (Arnold, 2008). 


\subsubsection{Willingness to pay}

We are interested in evaluating the average willingness to pay of individuals to decrease the monthly leasing cost of the battery in the 'base case' scenario. The individual willingness to pay $W T P(\text { Battery })_{n}$ is given by the ratio of the coefficient measuring the effect of the battery lease on the choice and the coefficient measuring the effect of the purchase price on the choice. The average value $W T P$ (Battery) is given by the weighted sum of all individual WTPs:

$$
\begin{aligned}
& W T P(\text { Battery }) \\
& =\sum_{n=1}^{N} w_{n} \operatorname{WTP}_{n}(\text { Battery }) \\
& =\sum_{n=1}^{N} w_{n} \frac{-\exp \left(\beta_{\mathrm{Battery}}+\beta_{\mathrm{AttL}} \cdot \mathrm{AttL}_{n}\right)}{-\exp \left(\beta_{\mathrm{price}_{\mathrm{RE}, \mathrm{TG} 12}} \cdot{\mathrm{TG} 12_{n}}_{n}+\beta_{\mathrm{price}_{\mathrm{RE}, \mathrm{TG} 3}} \cdot \mathrm{TG} 3_{n}+\beta_{\mathrm{price}_{\mathrm{RE}, \mathrm{TG} 45}} \cdot \mathrm{TG}_{4}+5_{n}+\beta_{\mathrm{AttC}} \cdot \mathrm{AttC}_{n}\right)}
\end{aligned}
$$

Here, variables $A t t L_{n}$ and $A t t C_{n}$ are the average values of the pro-leasing and proconvenience attitudes for an individual $n$. They are obtained by evaluating only the deterministic part $\beta_{\mathrm{Mean} j}+\sum_{i} \beta_{j, i} X_{j, i}$ of Equations (1) and (2).

A simulation of this indicator leads to an average value of WTP of 111.35. This means that individuals are ready to pay $111.35 \mathrm{CHF}$ more on the purchase price of an electric car if the monthly cost of leasing the battery is decreased by 1 CHF. This value approximately corresponds to the amount of money an individual would additionally pay on the battery leasing cost, if he keeps his car for 9 years and 3 months.

The results of the estimation of the SP model have shown that individuals from different target groups have different sensitivities to changes in the price of the electric car. Therefore their WTPs for a decrease in the battery lease might also differ. The WTP for a target group $T G$ is computed as follows:

$$
W T P_{\mathrm{TG}}(\text { Battery })=\frac{\sum_{n=1}^{|\mathrm{TG}|} w_{n} W T P_{n}(\text { Battery })}{\sum_{n=1}^{|\mathrm{TG}|} w_{n}}
$$

The values of WTP for a decrease in the battery lease for each target group are reported in Table 15. We notice that the WTP for Renault customers is much lower than for other target groups. 


\begin{tabular}{rlr}
\hline Number & Target group & WTP(Battery) \\
\hline 1,2 & Recent and prospective buyers & 117.55 \\
3 & Renault customers & 57.00 \\
4,5 & Future Renault customers and newsletter members & 93.05 \\
\hline & All target groups & 111.35 \\
\hline
\end{tabular}

Table 15: Values of WTP for a decrease in the monthly rent of the battery by target group and over the whole population.

In order to understand how the individual WTPs vary according to the decisionmaker's attitudes, we represent them against $A t t C$ and $A t t L$. Figure 5 shows the individual WTPs obtained from the application of the choice model for forecasting on the forecasting sample as a function of the two attitudes. We observe two trends. First, the higher the pro-convenience attitude is, the higher the WTP is (see Figure 5(a)). Second, the lower the pro-leasing attitude is, the higher the WTP is (see Figure 5(b)). Moreover we can distinguish three clusters on each graph. They represent observations from the different target groups, where observations on the top of the graph are from target groups 1 and 2, observations in the middle are from target groups 4 and 5 , and observations at the bottom are from target group 3.

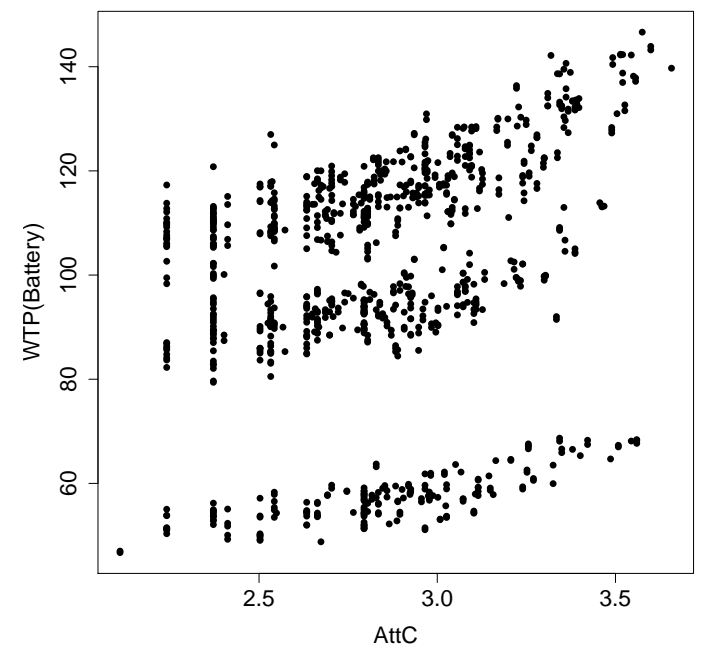

(a) $W T P$ (Battery) as a function of $A t t C$.

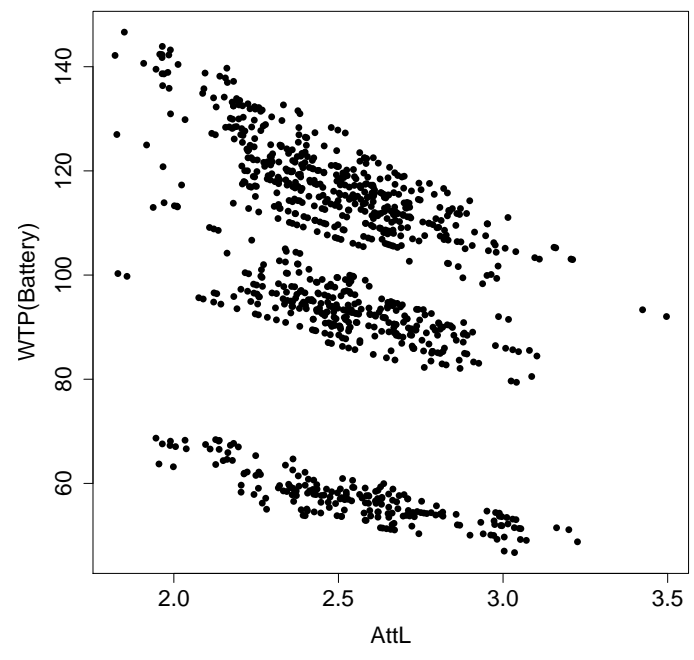

(b) $W T P$ (Battery) as a function of $A t t L$.

Figure 5: WTP relative to a decrease in the monthly battery leasing cost, as a function of attitudes $A t t C$ and $A t t L$. 


\section{Discussion}

The importance of developing an operational model such as the one presented in this paper is justified by the needs of the industry. In the case of the demand for Renault electric cars, it contributes to the identification of an optimal pricing strategy for Renault and to the characterization of target customers.

In particular, the introduction of a large incentive $(-5,000 \mathrm{CHF})$ on the purchase price of an electric vehicle can promote its choice, while too high operating costs (5.40 CHF / $100 \mathrm{~km}$ ) can discourage it. Individuals are willing to pay about 1,110 CHF more on the purchase price of an electric car if the monthly leasing cost of the battery is decreased by $10 \mathrm{CHF}$. The car manufacturer maximizes his average revenue if electric vehicles are sold at a price between 30,000 $\mathrm{CHF}$ and 35,000 CHF.

Target customers are mainly public transport users, in households owning several cars, with high incomes, living in German- or Italian-speaking regions of Switzerland and rather young. The presence of the pro-leasing attitude shows that individuals in favor of leasing contracts are less affected by changes in the monthly battery rent. Similarly, the introduction of the pro-convenience attitude demonstrates that changes in the purchase price penalizes individuals who choose a car based on its practical aspects less than those who choose it according to its design.

\section{Conclusion}

In this paper, we presented a comprehensive methodology which aims at evaluating the demand for a non-existing technology, i.e. electric vehicles. In order to obtain an operational model, it is important to go through a careful procedure, from an adequate data collection to a model application leading to realistic market shares.

This paper contributes to the achievement of an operational model by three aspects, i.e. the survey design, the modeling framework and the model application. Regarding data collection, we presented a method that corrects for selection biases resulting from the reduction of a full factorial design. It allows for a balanced selection of each configuration of levels. In terms of modeling, the inclusion of attitudes or perceptions in the choice model contributes to a better characterization of the unobserved factors affecting individuals' decisions. Finally, we developed a realistic model from SP data that can be applied to forecast demand shifts in the presence of a new alternative. In such a procedure, it is essential to integrate market information and take into account the population structure 
to forecast the market changes when a new product is introduced.

We expect that this paper will encourage more research based on advanced modeling techniques in contexts where attitudes and perceptions play a significant role, and where market information and SP data must be combined to get a full picture of the situation in a real context where new alternatives need to be analyzed.

Future works involve the analysis of the impact of the balanced selection of each profile in the fractional factorial design on its efficiency.

\section{Acknowlegdements}

The authors would like to thank Renault Suisse S.A. for providing information necessary to the creation of the survey and for funding this collaborative research. They particularly appreciated the help of Anne-Sophie Farfelan who brought her insight on the car survey context and her support and advice in the creation of the questionnaire. The authors would also like to acknowledge the market research company GfK Switzerland for implementing the online survey.

\section{References}

Abou-Zeid, M., Ben-Akiva, M., Bierlaire, M., Choudhury, C. and Hess, S. (2010). Attitudes and value of time heterogeneity, in E. V. de Voorde and T. Vanelslander (eds), Applied Transport Economics: A Management and Policy Perspective, De Boeck, pp. $523-545$.

Achtnicht, M., Bühler, G. and Hermeling, C. (2008). Impact of service station networks on purchase decisions of alternative-fuel vehicles, $Z E W$ Discussion Papers 08-088, Centre for European Economic Research (ZEW).

Alvarez-Daziano, R. and Bolduc, D. (2009). Canadian consumers' perceptual and attitudinal responses towards green automobile technologies: an application of hybrid choice models, 2009 EAERE-FEEM-VIU European Summer School in Resources and Environmental Economics: Economics, Transport and Environment, Venice International University.

Arnold, R. A. (2008). Economics, ninth edn, Cengage Learning, Mason.

Beggs, S., Cardell, S. and Hausman, J. (1981). Assessing the potential demand for electric cars, Journal of Econometrics 17(1): 1-19. 
Ben-Akiva, M., Gunn, H. F. and Silman, L. (1984). Disaggregate trip distribution models, Presentation for the Japanese society of civil engineers, Tokio (347).

Ben-Akiva, M. and Lerman, S. (1985). Discrete choice analysis: theory and application to travel demand, Vol. 9, The MIT Press.

Ben-Akiva, M., McFadden, D., Train, K., Walker, J., Bhat, C., Bierlaire, M., Bolduc, D., Boersch-Supan, A., Brownstone, D., Bunch, D., Daly, A., de Palma, A., Gopinath, D., Karlstrom, A. and Munizaga, M. A. (2002). Hybrid choice models: Progress and challenges, Marketing Letters 13(3): 163-175.

Bierlaire, M. and Fetiarison, M. (2009). Estimation of discrete choice models: extending BIOGEME., Proceedings of the 9th Swiss Transport Research Conference (STRC).

Brownstone, D., Bunch, D. S., Golob, T. F. and Ren, W. (1996). A transactions choice model for forecasting demand for alternative-fuel vehicles, Research in Transportation Economics 4: 87-129.

Brownstone, D., Bunch, D. S. and Train, K. (2000). Joint mixed logit models of stated and revealed preferences for alternative-fuel vehicles, Transportation Research Part B 34(5): 315-338.

Brownstone, D. and Train, K. (1999). Forecasting new product penetration with flexible substitution patterns, Journal of Econometrics 89: 109-129.

Bunch, D. S., Bradley, M., Golob, T. F., Kitamura, R. and Occhiuzzo, G. P. (1993). Demand for clean-fuel vehicles in california: A discrete-choice stated preference pilot project, Transportation Research Part A 27(3): 237-253.

Cherchi, E. and Ortúzar, J. d. D. (2006). On fitting mode specific constants in the presence of new options in rp/sp models, Transportation Research Part A: Policy and Practice 40(1): $1-18$.

Dagsvik, J. K., Wennemo, T., Wetterwald, D. G. and Aaberge, R. (2002). Potential demand for alternative fuel vehicles, Transportation Research Part B 36(4): 361-384.

Daly, A. and Rohr, C. (1998). Forecasting demand for new travel alternatives, in T. Gärling, T. Laitila and K. Westlin (eds), Theoretical foundations of travel choice modeling, Pergamon. 
Daziano, R. A. and Bolduc, D. (2013). Incorporating pro-environmental preferences towards green automobile technologies through a Bayesian hybrid choice model, Transportmetrica A: Transport Science 9(1): 74-106.

Ewing, G. and Sarigöllü, E. (2000). Assessing consumer preferences for clean-fuel vehicles: A discrete choice experiment, Journal of Public Policy $\& 3$ Marketing 19(1): 106-118.

Glerum, A., Thémans, M. and Bierlaire, M. (2011). Modeling demand for electric vehicles: the effect of car users' attitudes and perceptions, Proceedings of the Second International Choice Modeling Conference, Leeds, UK.

Horne, M., Jaccard, M. and Tiedemann, K. (2005). Improving behavioral realism in hybrid energy-economy models using discrete choice studies of personal transportation decisions, Energy Economics 27(1): 59-77.

Mannering, F. L. and Train, K. (1985). Recent directions in automobile demand modeling, Transportation Research Part B 19(4): 265-274.

McFadden, D. (1986). The choice theory approach to market research, Marketing Science 5(4): 275-297.

Mueller, M. G. and de Haan, P. (2009). How much do incentives affect car purchase? agent-based microsimulation of consumer choice of new cars-part i: Model structure, simulation of bounded rationality, and model validation, Energy Policy 37(3): 10721082.

Schiraldi, P. (2011). Automobile replacement: a dynamic structural approach, The RAND Journal of Economics 42(2): 266-291.

Train, K. (1980). The potential market for non-gasoline-powered automobiles, Transportation Research Part A 14(5-6): 405-414.

Train, K. (1986). Qualitative choice analysis: theory, econometrics, and an application to automobile demand, MIT Press series in transportation studies, MIT Press.

Train, K. and Wilson, W. W. (2008). Estimation on stated-preference experiments constructed from revealed-preference choices, Transportation Research Part B: Methodological 42(3): 191-203.

Walker, J. and Ben-Akiva, M. (2002). Generalized random utility model, Mathematical Social Sciences 43(3): 303-343. 
Walker, J. L. (2001). Extended Discrete Choice Models: Integrated Framework, Flexible Error Structures, and Latent Variables, $\mathrm{PhD}$ thesis, Massachusetts Institute of Technology. 


\begin{tabular}{|c|c|c|c|}
\hline Utilities & $\mathrm{CG}$ & RG & $\mathrm{RE}$ \\
\hline \multicolumn{4}{|l|}{ Linear terms } \\
\hline$A S C_{\mathrm{CG}}$ & 1 & - & - \\
\hline$A S C_{\mathrm{RG}}$ & - & 1 & - \\
\hline$\beta_{\text {UseCostGasoline }}$ & UseCostGasoline $_{\mathrm{CG}}$ & UseCostGasoline $_{\mathrm{RG}}$ & - \\
\hline$\beta_{\text {UseCostElecHigh }}$ Fluence & - & - & UseCostElecHigh · Fluence \\
\hline$\beta_{\text {UseCostElecHigh Zoé }}$ & - & - & UseCostElecHigh · Zoé \\
\hline$\beta_{\text {UseCostElecMed Zoé }}$ & - & - & UseCostElecMed · Zoé \\
\hline$\beta_{\text {IncentiveHigh }}$ & - & - & IncentiveHigh \\
\hline$\beta_{\text {IncentiveMed }}$ & - & - & IncentiveMed \\
\hline$\beta_{\text {IncentiveLow }}$ & - & - & IncentiveLow \\
\hline$\beta_{\mathrm{PT}_{\mathrm{CG}, \mathrm{TG} 1245}}$ & $\mathrm{PT} \cdot \mathrm{TG} 1245$ & - & - \\
\hline$\beta_{\mathrm{PT} \mathrm{RG}_{\mathrm{TG} 1245}}$ & - & $\mathrm{PT} \cdot \mathrm{TG} 1245$ & - \\
\hline$\beta_{\mathrm{PT}_{\mathrm{CG}, \mathrm{TG} 3}}$ & $\mathrm{PT} \cdot \mathrm{TG} 3$ & - & - \\
\hline$\beta_{\mathrm{PT}_{\mathrm{RG}, \mathrm{TG} 3}}$ & - & $\mathrm{PT} \cdot \mathrm{TG} 3$ & - \\
\hline$\beta_{\mathrm{SitFam}} \mathrm{CG}$ & SitFam & - & - \\
\hline$\beta_{\text {SitFam }_{\mathrm{RG}}}$ & - & SitFam & - \\
\hline$\beta_{\text {Income }_{\mathrm{CG}}}$ & Income & - & - \\
\hline$\beta_{\text {Income RG }_{\text {R }}}$ & - & Income & - \\
\hline$\beta_{\mathrm{NbCars}}{ }_{\mathrm{CG}, \mathrm{TG} 1245}$ & NbCars · TG1245 & - & - \\
\hline$\beta_{\mathrm{NbCarsRG}, \mathrm{TG} 1245}$ & - & NbCars · TG1245 & - \\
\hline$\beta_{\mathrm{NbCars}_{\mathrm{CG}, \mathrm{TG} 3}}$ & NbCars · TG3 & - & - \\
\hline$\beta_{\mathrm{NbCars}_{\mathrm{RG}, \mathrm{TG} 3}}$ & - & NbCars · TG3 & - \\
\hline$\beta_{\text {French }_{\mathrm{CG}}}$ & French & - & - \\
\hline$\beta_{\text {French }_{\mathrm{RG}}}$ & - & French & - \\
\hline$\beta_{\mathrm{Age}_{\mathrm{CG}}}$ & Age & - & - \\
\hline$\beta_{\mathrm{Age}_{\mathrm{RG}}}$ & - & Age & - \\
\hline$\beta_{\mathrm{TG} 12_{\mathrm{CG}}}$ & TG12 & - & - \\
\hline$\beta_{\mathrm{TG} 12 \mathrm{RG}}$ & - & TG12 & - \\
\hline$\beta_{\mathrm{TG} 3_{\mathrm{CG}}}$ & TG3 & - & - \\
\hline$\beta_{\mathrm{TG} 3_{\mathrm{RG}}}$ & - & TG3 & - \\
\hline \multicolumn{4}{|l|}{ Non-linear terms } \\
\hline $\begin{array}{l}-\exp \left(\beta_{\text {price }_{\mathrm{CG}}}\right. \\
\left.+\beta_{\mathrm{AttC}} \cdot \mathrm{AttC}\right) \\
-\exp \left(\beta_{\text {price }_{\mathrm{RG}, \mathrm{TG} 1245} \cdot \mathrm{TG} 1245}\right. \\
+\beta_{\text {price }_{\mathrm{RG}, \mathrm{TG} 3} \cdot \mathrm{TG} 3} \\
\left.+\beta_{\mathrm{AttC}} \cdot \mathrm{AttC}\right) \\
-\exp \left(\beta_{\text {price }_{\mathrm{RE}, \mathrm{TG} 12}} \cdot \mathrm{TG} 12\right. \\
+\beta_{\text {price }_{\mathrm{RE}, \mathrm{TG} 3}} \cdot \mathrm{TG} 3 \\
+\beta_{\text {price }_{\mathrm{RE}, \mathrm{TG} 45}} \cdot \mathrm{TG} 45 \\
\left.+\beta_{\mathrm{AttC}} \cdot \mathrm{AttC}\right) \\
-\exp \left(\beta_{\mathrm{Battery}}\right. \\
\left.+\beta_{\mathrm{AttL}} \cdot \mathrm{AttL}\right)\end{array}$ & - & $\begin{array}{l}- \\
---------- \\
\text { price }_{\mathrm{RG}} \\
----------\end{array}$ & $\begin{array}{l}- \\
-------------- \\
- \\
---------------\end{array}$ \\
\hline
\end{tabular}

Table 6: Specification table of the utilities. 


\begin{tabular}{|c|c|c|c|c|c|}
\hline Name & Value & $t$-test & Name & Value & $t$-test \\
\hline \multicolumn{3}{|c|}{ Parameters in linear terms } & \multicolumn{3}{|c|}{ Parameters in linear terms (ctd) } \\
\hline$A S C_{\mathrm{CG}}$ & -2.71 & -4.77 & $\beta_{\text {Income }_{\mathrm{CG}}}$ & $-0.223^{*}$ & -1.92 \\
\hline$A S C_{\mathrm{RG}}$ & -2.17 & -3.63 & $\beta_{\text {Income }_{\mathrm{RG}}}$ & -0.259 & -2.25 \\
\hline$\beta_{\text {UseCostGasoline }}$ & $-0.0469 * *$ & -1.41 & $\beta_{\text {French }_{\mathrm{CG}}}$ & 0.373 & 2.94 \\
\hline$\beta_{\text {UseCostElecHigh }}$ Fluence & -0.264 & -2.20 & $\beta_{\text {French }_{\mathrm{RG}}}$ & $0.0254^{* *}$ & 0.19 \\
\hline$\beta_{\text {UseCostElecHigh Zoé }}$ & -0.802 & -4.82 & $\beta_{\mathrm{Age}_{\mathrm{CG}}}$ & 0.0172 & 3.65 \\
\hline$\beta_{\text {UseCostElecMed Zoé }}$ & -0.514 & -3.21 & $\beta_{\text {Age }_{\text {RG }}}$ & $-0.00210^{* *}$ & -0.43 \\
\hline$\beta_{\text {IncentiveHigh }}$ & 0.799 & 6.21 & $\beta_{\mathrm{TG} 122_{\mathrm{CG}}}$ & 1.60 & 4.57 \\
\hline$\beta_{\text {IncentiveMed }}$ & $0.0538^{* *}$ & 0.40 & $\beta_{\mathrm{TG} 12_{\mathrm{RG}}}$ & $0.664^{*}$ & 1.89 \\
\hline$\beta_{\text {IncentiveLow }}$ & $0.0164^{* *}$ & 0.12 & $\beta_{\mathrm{TG} 3_{\mathrm{CG}}}$ & $0.104^{* *}$ & 0.11 \\
\hline$\beta_{\mathrm{PT}_{\mathrm{CG}, \mathrm{TG} 1245}}$ & -0.259 & -1.96 & $\beta_{\mathrm{TG} 3_{\mathrm{RG}}}$ & 2.63 & 5.18 \\
\hline$\beta_{\mathrm{PT}_{\mathrm{RG}, \mathrm{TG} 1245}}$ & -0.577 & -3.67 & \multicolumn{3}{|c|}{ Parameters in non-linear terms } \\
\hline$\beta_{\mathrm{PT}_{\mathrm{CG}, \mathrm{TG} 3}}$ & -2.64 & -3.85 & $\beta_{\text {price }_{\text {CG }}}$ & -3.60 & -4.77 \\
\hline$\beta_{\mathrm{PT}_{\mathrm{RG}, \mathrm{TG} 3}}$ & -1.17 & -4.40 & $\beta_{\text {price }_{\text {RG,TG1245 }}}$ & -1.39 & -4.33 \\
\hline$\beta_{\text {FamSit }_{\mathrm{CG}}}$ & $-0.157^{* *}$ & -1.37 & $\beta_{\text {price }_{\mathrm{RG}, \mathrm{TG} 3}}$ & $-0.290^{* *}$ & -1.06 \\
\hline$\beta_{\text {FamSit }_{\mathrm{RG}}}$ & $0.183^{* *}$ & 1.56 & $\beta_{\text {price }_{\mathrm{RE}, \mathrm{TG} 12}}$ & -0.365 & -2.57 \\
\hline$\beta_{\mathrm{NbCars}}{ }_{\mathrm{CG}, \mathrm{TG} 1245}$ & -0.207 & -2.75 & $\beta_{\text {price }_{\mathrm{RE}, \mathrm{TG} 3}}$ & 0.342 & 2.10 \\
\hline$\beta_{\mathrm{NbCars} R G, \mathrm{TG} 1245}$ & -0.193 & -2.32 & $\beta_{\text {price }_{\mathrm{RE}, \mathrm{TG} 45}}$ & $-0.152^{* *}$ & -1.33 \\
\hline$\beta_{\mathrm{NbCars} \mathrm{CG}, \mathrm{TG} 3}$ & $-0.664^{*}$ & -1.88 & $\beta_{\mathrm{AttC}}$ & -0.142 & -4.93 \\
\hline \multirow[t]{2}{*}{$\beta_{\mathrm{NbCars} R \mathrm{R}, \mathrm{TG} 3}$} & -0.945 & -6.24 & $\beta_{\text {Battery }}$ & 2.17 & 5.87 \\
\hline & & & $\beta_{\mathrm{AttL}}$ & $-0.193^{*}$ & -1.74 \\
\hline
\end{tabular}

Table 11: Estimates of the parameters of the choice model, with values of $t$-test. (** Statistical significance $<90 \%,{ }^{*}$ Statistical significance $\left.<95 \%\right)$. 